\title{
Dynamic Panel Data Analysis of the Impact of Climatic Shocks on Food- security
}

\author{
Zouhaier Hadhek ${ }^{*}, 1$ and Sawssen Nafti ${ }^{2}$ \\ ${ }^{1}$ University of Gabès Higher Institute of Management of Gabès . \\ ${ }^{2}$ Faculty of Economics and Management of Sousse.
}

\begin{abstract}
The present work attempts to address the problem of promoting sustainable food safety in a world constrained by land, water and energy. Firstly, by analyzing the impact of economic growth on FS. Then via the determination of the impact of CC on FS. Finally through the analysis of the relationship between the economic growth and $\mathrm{CO} 2$ emissions for developing countries with different samples and different empirical studies.
\end{abstract}

Keywords : Food safety- economic growth - CC - CO2 Emission.

JEL Classification: Q18- O4- Q54- F1

\section{INTRODUCTION}

It is known that the greenhouse gasesare continuously heating up the surface of the planet (Intergovernmental Panel on CC IPCC, 2007). This, in turn, leads to future hot climates and causes changes in rainfall patterns, which have serious negative effectson both developed and developing countries(IPCC, 2007). Forecasts,published by the US National Center for Atmospheric Research, expectations show thatthe precipitation downward trend will continue until 2050. In particular, South Africa will beat 10 to $20 \%$ drier than the last 50 years (Mitchell and Tanner, 2006).On the other hand, it is known that these climatic changes(CC) are affecting the agricultural productivity, the FS and other sectors across spatial and temporal scales. In the tropics, particularly in Africa, the CCareexpected to be damagingthe agricultural livelihoods (Dinar et al., 2008, Dixon et al., 2001). According to the International Assessment of Agricultural Knowledge, Science and Technology for Development (IAASTD, 2009), theCC are coinciding with the increasing demand for food, feed, fiber and fuel. This has a potential to irreversibly damaging the base of the natural resources whilethe agriculture is depending to those latter.As a result, the CC has important consequences on theFS (FS).

A now day, the study of the impact of the climatic changes and their consequences on the FS is crucial in order to protect the future of the humanity.In fact, the FS can be defined as a situation in which human can get a physical, social and economic access to sufficient, nutritious and healthy nourishment. This leads to satisfy to their alimentary needs and preferences. Several authors have reported the measurement of the effect of variables attributed to the climatic changes, but using static panel modeland/or classical simulation techniques. However, it should be noticed that the most of these

*Address correspondence to this author at University of Gabès Higher Institute of Management of Gabès Email: hzouhair2000@yahoo.fr studies are in a microeconomic scale for example, in Kenya,Kabubo-Mariara andKabara (2015) estimated the effects of climate change on food insecurity for the period (19752012).In Tunisia, Ben Zaied and Zouabi (2015) estimated the long run impact of climate variability on olive crop in Tunisia, using data for 24 regions from 1980 until 2012. Empirical results showed that temperature increase and rainfall shortages had negative long-run effects on olive production, across regions, over the last three decades.Later on, some papers have adopted the same model to study climate change impacts on food security in African countries (Kinda, 2017; Singh,2018). However, the main shortage of this model is that it has not studied the fourdimensions of food security

The present work reports the impact of the climatic changes on the FS in fifty-four developing countries belongs to Africa, Asia and Latin America, in the period range between 1960-2014, but using the dynamic panel data. The dispersion of the FS corresponding to the $\mathrm{CC}$ was verified in order curry out the econometric study. Furthermore, five variables were taken into account for the estimation of the impact on the FS; (i) CC, (ii) Democracy, (iii) Population Growth (PG), (iv) vulnerability prices(VULP) and (v) the Gross Domestic Product (GDP). The obtained results were deeply studied in order to analyze, evaluate and interpret the effect of the investigated variables of the FS.

\section{METHODOLOGICAL ANALYSES}

It was considered the model presentedin the following heterogeneous dynamic Panel:

$y_{i, t}=\alpha_{i}+\lambda_{i} y_{i, t-1}+\beta_{i}^{\prime} X_{i, t}+\varepsilon_{i, t}$

Where(i)is the individuals, (t) denotes the time dimension, $(\alpha)$ is a constant indicating the shape of the curve, $(\lambda)$ is the coefficient associated to the past of the exogenous variable, 
$\left(\beta^{\prime}\right)$ is a coefficient relative to the quadratic term and $(\varepsilon)$ is the error term.

The long-term effect was calculated as follows:

$\theta_{i}=\frac{\beta_{i}}{1-\lambda_{i}}$

With, $\beta=E\left(\beta_{i}\right) ; \lambda=E\left(\lambda_{i}\right) ; \theta=E\left(\theta_{i}\right)=E\left(\frac{\beta_{i}}{1-\lambda_{i}}\right)$

Assuming the heterogeneity of coefficients $\left(\beta_{i} \neq \beta ; \lambda_{i} \neq \lambda\right)$ the fixed effect estimators are not consistent. This nonconvergence is due to the emergence of the next composed error:

$\omega_{i t}=\left(\beta_{i}-\beta\right) x_{i t}+\left(\lambda_{i}-\lambda\right) y_{i t-1}+u_{i t}$

The presence of a serial correlation between $x_{i, t}$, allows the identification of heterogeneitybias that affects the quality of estimators. Indeed, Pesaran and Shin (1995) consider the case where $x_{i, t}$ is generated by an autoregressive process of order 1 , which reads as follows:

$x_{i, t}=\mu_{i}(1-\phi)+\phi x_{i, t-1}+u_{i, t}$

With $E\left(x_{i, t}\right)=\mu$ and $u_{i, t} \rightarrow i i d\left(0, \delta_{i}^{2}\right)$. When $\rho \rightarrow 1$, that is to say $x_{i, t}$ tends to be integrated of order 1 , the probability limits of fixed effect estimators $(\hat{\beta}, \hat{\lambda})$ when $N \rightarrow \infty$ and $T \rightarrow \infty$ are given by:

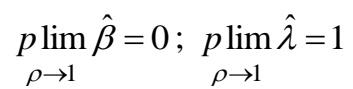

This result shows that the estimators $(\hat{\beta}, \hat{\lambda})$ do not converge to their true value butto the long-term estimator, $\hat{\theta}=\frac{\hat{\beta}}{1-\hat{\lambda}}$ the asymptotic biasis zero, it is not a problem since the respective biasof the numerator and denominator tend to cancel each other. At this level, the use of the estimator of the group average that is convergent for large values of $\mathrm{N}$ and $\mathrm{T}$.

In fact, the idea of Pesaran and Smith is to transform at first the short-term coefficients into random coefficients.

$\beta_{i}=\beta+\eta_{1 i} ; \lambda_{i}=\lambda+\eta_{2 i}$

In a second step, the long-term coefficients are processed as follows:

$\psi_{i}=\frac{\lambda_{i}}{1-\lambda_{i}}=\psi+\varepsilon_{1, i}$

$\theta_{i}=\frac{\beta_{i}}{1-\lambda_{i}}=\theta+\varepsilon_{2, i}$
With: $\eta_{1, i}, \eta_{2, i}, \varepsilon_{1, i}$ and $\varepsilon_{2, i}$ are all terms of zero expectation errors and of constant variance. Finally the estimator of the average of the groups $\hat{\theta}_{M G}$ and $\theta$ is given by:

$\theta_{M G}=N^{-1} \sum_{i=1}^{N} \frac{\widehat{\beta}_{i}}{1-\hat{\lambda}_{i}}$

With $\hat{\beta}_{i}$ and $\hat{\lambda}_{i}$ are individual fixed effects estimators.

An extension was made by Pesaran, Shin and Smith (1999) who suggested the estimator pooledmean group (PMG below). This estimator is built under the assumption of heterogeneity of short-term coefficients and long-term homogeneity of slope coefficients (Pesaran et al. 1999).

The estimate is based on the ARDL model (autoregressive distributed lag) of (pi,qi) order as follows:

$$
\begin{aligned}
& \Delta y_{i t}=\phi_{i} y_{i, t-1}+\beta_{i} x_{i, t}+\sum_{j=1}^{p_{i}-1} \Psi_{i, j} \Delta y_{i, t-j}+\sum_{j=1}^{p_{i}-1} \delta_{i, j} \Delta x_{i, t-j} \\
& +\alpha_{i}+\varepsilon_{i, t}
\end{aligned}
$$

Where $y_{i, t}$ is the dependent variable, $x_{i, t}$ the vector of explanatory variables, $\alpha_{i}$ is a coefficient that captures the countryspecificity, $\Psi_{i j}$ and $\delta_{i, t}$ represent the short-term dynamic coefficients for each country and $\varepsilon_{i, t}$ is the error term of the model.

The PMG estimator is based on a panel modeling of ARDL model, which can be written as an error correction model.

The basic equation is based on the following dynamic panel data modeling:

$$
\begin{aligned}
& F S_{i, t}=\alpha_{i}+\lambda_{i} F S_{i, t-1}+\beta_{i, t-1} \text { VULCS }_{i, t}+\beta_{2, i} \text { VULPRICE }_{i, t} \\
& +\omega_{1, i} E G_{i, t}+\omega_{2, i} \text { POPGROWTH }{ }_{i, t}+\omega_{3, i} \text { DEMOCRACIE } \\
& +\varepsilon_{i, t}
\end{aligned}
$$

Where :

- FS is the measure of the FS that touches the component of food availability per capita. We use the offer of food per capita as a food safety measurement. This measure is calculated as the sum of production and trade balance of food, we deduct the value of any use other than human consumption. In our work, the foods used are: corn, millet, rice, sorghum, soybean, sugar and wheat. The offer of food is obtained by an arithmetic average of the offers of selected foods expressed in $\mathrm{kcal} /$ person / year.

- VULCS is the variable of CC measured as the average Height of rainfall ( $\mathrm{mm}$ per year). Average precipitation in depth is the long-term average (in space and time) of annual precipitation in the country. Precipitation is defined as any kind of water that falls from clouds as a liquid or a solid. This 
Table 1. Descriptive statistics: Total Sample.

\begin{tabular}{|c|c|c|c|c|c|c|}
\hline & POPGROWTH & VULPRICE & EG & FS & DEMOCRATIE & VULCS \\
\hline MEAN & 2.421768 & 1.617762 & 0.017005 & 34.81995 & 0.161013 & 736.3943 \\
\hline MAXIMUM & 11.18066 & 6.563665 & 1.037997 & 404.0000 & 10.0000 & 3240.000 \\
\hline STD. DEV. & 1.112806 & 0.931232 & 0.064293 & 27.90685 & 273.2164 & 959.1257 \\
\hline SKEWNESS & 0.935466 & 1.084903 & -0.556967 & 3.533400 & 6.998247 & 1.419150 \\
\hline KURTOSIS & 13.44311 & 4.527617 & 66.51142 & 40.64178 & 50.01020 & 3.489281 \\
\hline
\end{tabular}

Table 2. Descriptive statistics: Asia.

\begin{tabular}{|c|c|c|c|c|c|c|}
\hline & DEMOCRATIE & FS & EG & VULPRICE & VULCS & POPGROWTH \\
\hline MEAN & -0.996416 & 39.45455 & 0.028042 & 1.586293 & 1151.300 & 2.570305 \\
\hline MEDIAN & -2.000000 & 36.00000 & 0.028682 & 1.417479 & 361.0000 & 2.506545 \\
\hline MAXIMUM & 10.00000 & 404.0000 & 1.037997 & 4.964836 & 2875.000 & 11.18066 \\
\hline MINIMUM & -10.00000 & 2.000000 & -1.049744 & 0.147126 & 25.00000 & -0.190972 \\
\hline STD. DEV. & 7.067511 & 40.26778 & 0.096973 & 0.913148 & 1239.710 & 1.203566 \\
\hline SKEWNESS & 0.127707 & 5.195527 & -0.282101 & 0.774009 & 0.404826 & 2.050879 \\
\hline KURTOSIS & 1.381334 & 42.53348 & 58.33284 & 3.298253 & 1.237338 & 13.05299 \\
\hline JARQUE-BERA & 62.43362 & 16847.94 & 68513.17 & 43.07875 & 18.81257 & 2971.737 \\
\hline PROBABILITY & 0.000000 & 0.000000 & 0.000000 & 0.000000 & 0.000082 & 0.000000 \\
\hline
\end{tabular}

variable was derived from the data base of the World Bank.

- VULPRICE is the vulnerability to shocks in food prices using the procedure developed by Combesand al. (2012). To calculate the vulnerability index, we use the technique of principal component analysis (PCA) using three variables; (i) the share of food imports in total consumption of households, (ii) the ratio of imports of foodstuffs to total imports of goods and services and (iii) the reverse of the level of GDP per capita. We use the reverse of the level of GDP per capita to be assured that the level of development is negatively correlated to the degree of vulnerability to food price shocks. We normalize the index so that it will vary between 0 and 10 . Higher values corresponding to high levels of vulnerability.

- $\quad$ EG is explained by the GDP is the variable related to income: GDP per capita. Data are expressed in dollars. This variable was derived from the data base of the World Bank;
- $\quad$ POP is the growth rate of the population. This variable was derived from the data base of the World Bank;

- Democratie is the variable related to democracy. This variable is measured by the democracy index and the index of autocracy (Polity 2), and on a scale of +10 (democracy) to -10 (autocracy). Polity on the findings of the level of democracy of a State is based on an assessment of elections in that State in terms of competition, openness and level of participation. This variable was taken from the Polity IV data base:Individual Country Trends Regime, 19462013.

\section{DATA AND DESCRIPTIVE ANALYSIS}

The objective of this work consists to validate the impact of climatic shocks on the FS in 54 developing countries. The study period runs from 1960 to 2014. The main feature of our sample is its heterogeneity in the level of FS, climate and economic growth (EG). To overcome this heterogeneity, we will appeal to the modeling dynamic panel data. The estima- 
Table 3. Descriptive statistics: African Countries.

\begin{tabular}{|c|c|c|c|c|c|c|}
\hline & POPGROWTH & VULPRICE & EG & FS & DEMOCRATIE & VULCS \\
\hline MEAN & 2.664870 & 1.974589 & 0.012873 & 34.93721 & -2.801109 & 363.6716 \\
\hline MEDIAN & 2.677820 & 1.792177 & 0.016627 & 33.00000 & -5.000000 & 220.0000 \\
\hline MAXIMUM & 11.03389 & 6.563665 & 0.315742 & 98.00000 & 9.000000 & 2526.000 \\
\hline MINIMUM & -6.342817 & 0.128566 & -0.648605 & 0.000000 & -9.000000 & 5.000000 \\
\hline STD. DEV. & 1.067503 & 0.965887 & 0.058577 & 23.95080 & 5.622049 & 493.6007 \\
\hline SKEWNESS & 0.666019 & 0.989164 & -1.126300 & 0.391725 & 0.719160 & 2.941499 \\
\hline KURTOSIS & 18.70891 & 4.559267 & 18.20068 & 2.433077 & 2.033842 & 13.19396 \\
\hline JARQUE-BERA & 16517.84 & 228.9521 & 14000.82 & 24.82166 & 37165.81 & 1968.229 \\
\hline PROBABILITY & 0.000000 & 0.000000 & 0.000000 & 0.000004 & 0.000000 & 0.000000 \\
\hline
\end{tabular}

Table 4. Descriptive statistics: Latin America.

\begin{tabular}{|c|c|c|c|c|c|c|}
\hline & POPGROWTH & VULPRICE & EG & FS & DEMOCRATIE & VULCS \\
\hline MEAN & 1.959390 & 0.962001 & 0.017776 & 30.74074 & 1219.600 \\
\hline MEDIAN & 2.000815 & 0.881646 & 0.022386 & 29.00000 & 8.000000 \\
\hline MAXIMUM & 3.813362 & 2.691368 & 0.150424 & 96.00000 & 10.00000 & 3240.000 \\
\hline MINIMUM & -0.064118 & 0.272250 & -0.153098 & 0.000000 & -9.000000 & 30.00000 \\
\hline STD. DEV. & 0.758082 & 0.399359 & 0.039346 & 22.26474 & 6.309451 & 1207.112 \\
\hline SKEWNESS & -0.279986 & 0.844227 & -1.013842 & 0.627953 & -1.100991 \\
\hline KURTOSIS & 2.751029 & 3.964173 & 5.781845 & 2.951282 & 2.586371 \\
\hline JARQUE-BERA & 8.606461 & 74.50749 & 266.6287 & 14.21707 & 1.513778 \\
\hline PROBABILITY & 0.013525 & 0.000000 & 0.000000 & 0.000818 & 0.000000 \\
\hline
\end{tabular}

tion will be made by the most advanced techniques of group averages of Pesaran and Smith (1995) ${ }^{1}$.

Theexamination of descriptive statistics illustrated in the Tab.1-4 reveals that Asia continent has the better FS level in term of the food availability. In fact, the average of the FS variable is equal to 39.45 against 30.74 in the Latin American zone with the lowest value.While Africa can be considered as the most vulnerable zonecorresponding tothe food prices volatility. Indeed,the results showthat Africa has the highest average index compared to other regions, particularly to the Latin America.Furthermore, it should be noticed that the African zonehasthe poorest conditions. In fact, for exemple the rainaverage is around $363 \mathrm{~mm}$, while the Latin American zone has the highest value $(1219 \mathrm{~mm})^{2}$.

${ }^{1}$ Pesaran, M.H. and R.P.Smith(1995), «Estimating Long-Run Relationships Heterogeneous Panels », Journal of Econometrics, 68, pp. 70-113

${ }^{2}$ Data from Changi Climate Station
The results have show that the Asian zoneposses the best performance in terms of real growth per capita. Its annual growth rate is about $2.8 \%$ while the African zoneshows the lowest growth rate $(1.2 \%)$. Indeed, the Latin American zone seems to be the most democratic region basing on the average index whi was found to be equal to about 4.52. However, the African zone is the region characterized by autocracy, posting an average index of -2.80 .

\section{CORRELATION ANALYSIS}

The correlation matrix was calculated in order to estimate the relationship between the $\mathrm{FS}$ and the $\mathrm{CC}$ and between the economic growth rate (EG) and the food supply (FSP), in the studied zones. The analysis did not show a significant correlation between the mentioned terms.Tab.5-8 show the obtained results of the calculations. 
Table 5. Correlation Matrix: Total Sample.

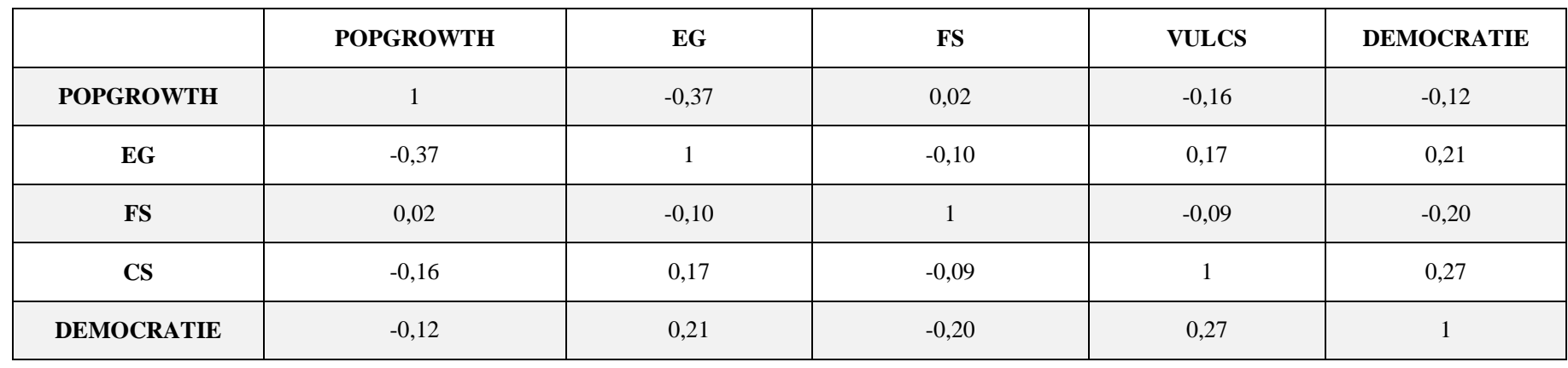

Table 6. CorrelationMatrix: Asia.

\begin{tabular}{|c|c|c|c|c|c|c|}
\hline & POPGROWTH & EG & VULPRICE & FS & VULCS & DEMOCRATIE \\
\hline POPGROWTH & 1,000 & 0,002 & 0,108 & $-0,064$ & 0,005 & $-0,007$ \\
\hline EG & 0,002 & 1,000 & 0,682 & $-0,178$ & $-0,194$ & $-0,537$ \\
\hline VULPRICE & 0,108 & 0,682 & 1,000 & $-0,012$ & $-0,162$ & $-0,575$ \\
\hline FS & $-0,064$ & $-0,178$ & $-0,012$ & 1,000 & $-0,138$ & $-0,088$ \\
\hline CS & 0,005 & $-0,194$ & $-0,162$ & $-0,138$ & 1,000 & 0,143 \\
\hline DEMOCRATIE & $-0,007$ & $-0,537$ & $-0,575$ & $-0,088$ & 0,143 & 1,000 \\
\hline
\end{tabular}

Table 7. Correlationmatrix: Latin America.

\begin{tabular}{|c|c|c|c|c|c|c|}
\hline & EG & POPGROWTH & VULPRICE & DEMOCRATIE & FS & VULCS \\
\hline EG & 1,00 & $-0,43$ & $-0,37$ & 0,20 & $-0,07$ & 0,29 \\
\hline POPGROWTH & $-0,43$ & 1,00 & 0,14 & $-0,24$ & 0,10 & 0,28 \\
\hline VULPRICE & $-0,37$ & 0,14 & 1,00 & $-0,27$ & 0,20 & $-0,15$ \\
\hline DEMOCRATIE & 0,20 & $-0,24$ & $-0,27$ & 1,00 & $-0,41$ & 0,00 \\
\hline FS & $-0,07$ & 0,10 & 0,20 & $-0,41$ & 1,00 & $-0,12$ \\
\hline$C S$ & 0,29 & 0,28 & $-0,15$ & 0,00 & $-0,12$ & 1,00 \\
\hline
\end{tabular}

Table 8. Correlationmatrix: Africa.

\begin{tabular}{|c|c|c|c|c|c|c|}
\hline & POPGROWTH & EG & FS & DEMOCRATIE & VULCS & VULPRICE \\
\hline POPGROWTH & 1,00 & $-0,61$ & 0,06 & 0,08 & $-0,19$ & 0,19 \\
\hline EG & $-0,61$ & 1,00 & $-0,21$ & $-0,11$ & $-0,07$ & 0,12 \\
\hline FS & 0,06 & $-0,21$ & 1,00 & 0,34 & 0,19 & $-0,19$ \\
\hline DEMOCRATIE & 0,08 & $-0,11$ & 0,34 & 1,00 & 1,00 & 0,03 \\
\hline CS & 0,19 & $-0,19$ & $-0,07$ & 0,19 & $-0,19$ & 0,03 \\
\hline
\end{tabular}

It can be noted that the EG is negatively correlated to the POPGROWTH while it is positively correlated to the Democratic variable.One can say that less the zone is populated and democratic more the EG is high. The variable related to
$\mathrm{CC}$ is positively correlated with democracy $(+0.21)$ : The Democratic countries in our sample are characterized by higher values of average precipitation. 
The analysis of the variables by zone shows that Asia is characterized by a positive correlation between the vulnerability of food prices to the GDP per capita while the Latin America shows a negative correlation. The African zone shows a positive correlation between the FSP and the democracy.

Fig. (1-4) summarize the correlation between the FSP and the CC. It is clear that, each was the zone the FS and CC are negatively correlated, except the African countries. The zone of the Latin America shows the most negative slope on the linear regression.

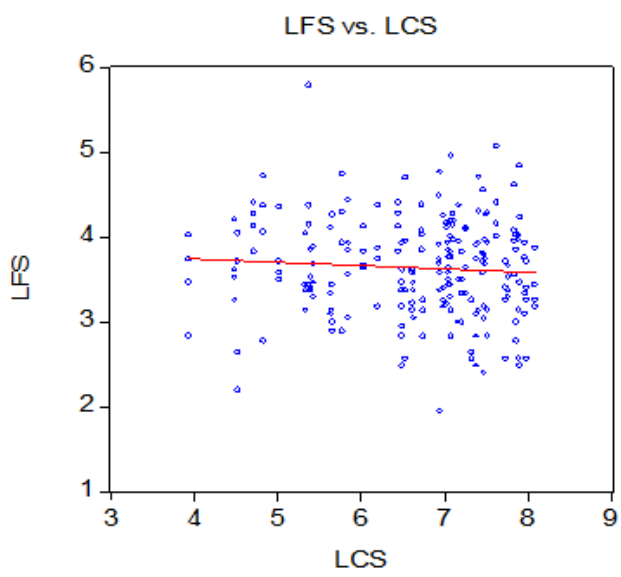

Fig. (1). Scatter of the FSversus the CC:Total sample.

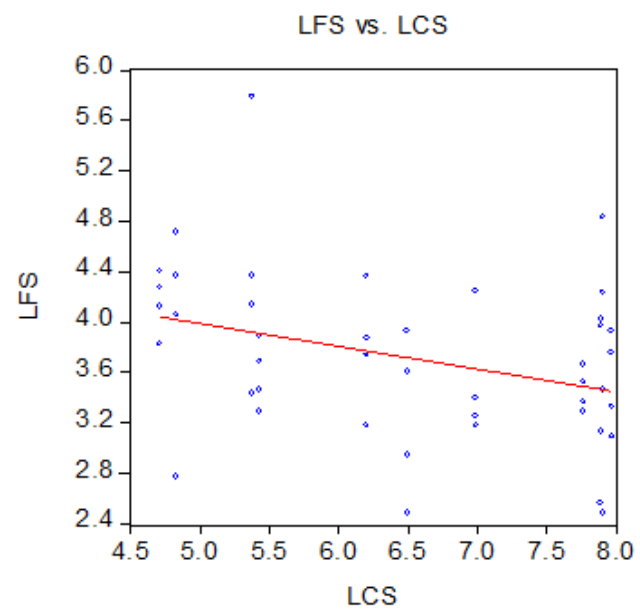

Fig. (2). The FS scatter versus theCC: Asia.

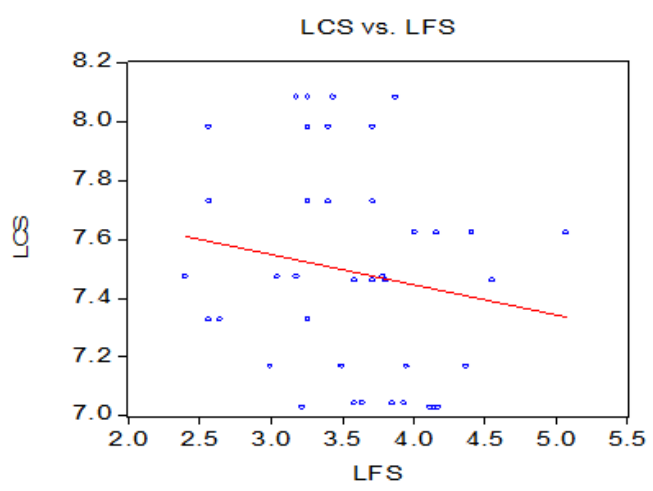

Fig. (3). The FS Scatter versus the CC: Latin America.

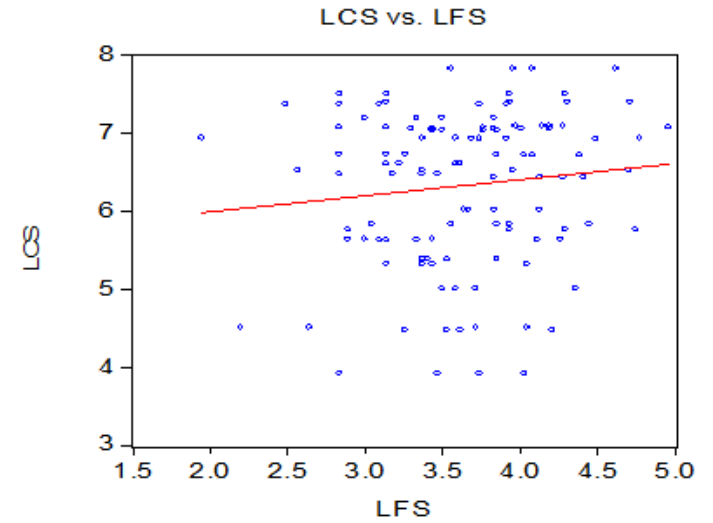

Fig. (4). FS Scatter versus the CC: Africa.

\section{EMPIRICAL ANALYSIS AND ESTIMATION RE- SULTS}

Knowing that the average technical groups are very significant and effective in the case of the dynamic panel, they were used for the estimation of the equations in the total sample and in eachzone (Asia, Africa and Latin America). A comparative study was made between the different effects of the $\mathrm{CC}$ and the vulnerability on the food prices and on the FS.

Table 9. Estimation resultsby the method of equation group's average (1) Total sample.

\begin{tabular}{|c|c|c|c|}
\hline & Coefficient & Std. Dev & T-student \\
\hline FS & $0.098^{* * * *}$ & 0.037 & 2.66 \\
\hline EG & $7.975^{* * *}$ & 1.18 & 7.13 \\
\hline Popgrowth & $-14.81^{* * *}$ & 0.96 & -15.31 \\
\hline Democratie & 0.014 & 0.01 & 1.46 \\
\hline Cc & $-0.0047 * * *$ & 0.0004 & -10.00 \\
\hline Constant & $131.15^{* * *}$ & 0.0004 & -10.09 \\
\hline
\end{tabular}

$* * *, * *$ and $*$ denote significance at respective rates of 1,5 and $10 \%$.

Table 10. Estimation Results by the Method of Equation Group's Average (2) Total Sample.

\begin{tabular}{|c|c|c|c|}
\hline & COEFFICIENT & STD. DEV & T-STUDENT \\
\hline FS & $0.328^{* * *}$ & 0.02 & 11.23 \\
\hline POPGROWTHI & -1.503 & 0.97 & 4.27 \\
\hline DEMOCRATIE & 0.003 & 7.63 & -0.19 \\
\hline VULPRICE & $-2.48 * * *$ & 0.002 & 1.35 \\
\hline CS & $-0.053 * * *$ & 0.001 & -8.15 \\
\hline CONSTANT & 138.33 & 94.16 & 1.46 \\
\hline
\end{tabular}

$* * *, * *$ and $*$ denote significance at respective rates of 1,5 and $10 \%$. 
Table 11. Estimation Results by the Method of Equation Group's Average(1) Asian Region.

\begin{tabular}{|c|c|c|c|}
\hline & Coefficient & Std. Dev & T-student \\
\hline$F S$ & $0.238^{* *}$ & 0.11 & 2.03 \\
\hline EG & $6.05^{* * *}$ & 1.32 & 4.46 \\
\hline Popgrowth & $-2.01 * * *$ & 0.287 & -7.01 \\
\hline Democratie & $1.34 *$ & 0.847 & 1.69 \\
\hline CS & $-0.014^{* * * *}$ & 0.00081 & -14.83 \\
\hline Constant & $515.80^{* * *}$ & 103.89 & 4.69 \\
\hline
\end{tabular}

$* * *, * *$ and $*$ denote significance at respective rates of 1,5 and $10 \%$.

Table 12. Results of Estimates by the Method of Equation Group's Average (2) Asian Region.

\begin{tabular}{|c|c|c|c|}
\hline & COEFFICIENT & STD. DEV & T-STUDENT \\
\hline FS & $0.408 * * *$ & 0.08 & 5.06 \\
\hline EG & $3.39 * * *$ & 0.58 & 5.78 \\
\hline POPGROWTHI & -0.49 & 1.50 & -0.32 \\
\hline VULPOCRATIE & 0.69 & 0.47 & 1.46 \\
\hline CS & $-0.20 * * *$ & 0.034 & -5.86 \\
\hline CONSTANT & $-0.0007 *$ & 0.0039 & -1.77 \\
\hline
\end{tabular}

$* * *, * *$ and $*$ denote significance at respective rates of 1,5 and $10 \%$.

Table 13. Estimation Results by the Method of Equation Group's Average (1) African Region.

\begin{tabular}{|c|c|c|c|}
\hline & Coefficient & Ecartype & T-student \\
\hline FS & $0.282^{* * *}$ & 0.044 & 6.28 \\
\hline Eg & $0.44 * * *$ & 0.029 & 14.70 \\
\hline Popgrowth & $-0.72^{* * *}$ & 0.109 & -6.66 \\
\hline Democratie & 0.008 & 0.0108 & 0.74126 \\
\hline CS & $-0.079^{*}$ & 0.033 & -2.39 \\
\hline Constant & $-180.36^{* * *}$ & 15.41 & -11.69 \\
\hline
\end{tabular}

$* * *, * *$ and $*$ denote significance at respective rates of 1,5 and $10 \%$.

Table 14. Estimation results by the method of equation group's average (2) African Region.

\begin{tabular}{|c|c|c|c|}
\hline & Coefficient & Ecartype & T-student \\
\hline$F S$ & $0.192 * * *$ & 0.058 & 3.30 \\
\hline$E G$ & $0.622 * * *$ & 0.054 & 11.14 \\
\hline
\end{tabular}

\begin{tabular}{|c|c|c|c|}
\hline Popgrowtht & $-0.42 * * *$ & 0.028 & -15.25 \\
\hline Democratie & 0.008 & 0.01 & 0.74 \\
\hline Vulprice & $-0.216 * * *$ & 0.024 & -8.72 \\
\hline CS & $-0.174 * * *$ & 0.018 & -9.68 \\
\hline Constant & $25.03 * * *$ & 2.19 & 11.39 \\
\hline
\end{tabular}

$* * *, * *$ and $*$ denote significance at respective rates of 1,5 and $10 \%$.

Table 15. Estimation Results by the Method of Equation Group's Average (1) Latin America Region.

\begin{tabular}{|c|c|c|c|}
\hline & Coefficient & Ecartype & T-student \\
\hline$F S$ & $0.538^{* * *}$ & 0.167 & 3.22 \\
\hline$E G$ & $2.12^{* * *}$ & 0.722 & 2.93 \\
\hline Popgrowth & $-3.79^{* * *}$ & 0.762 & -4.97 \\
\hline Democratie & 0.287 & 0.334 & 0.39 \\
\hline CS & $-0.002^{* * *}$ & 0.0003 & -7.39 \\
\hline Constant & 28.40 & 63.71 & 0.44 \\
\hline
\end{tabular}

$* * *, * *$ and $*$ denote significance at respective rates of 1,5 and $10 \%$.

Table 16. Estimation Results by Method of Equation Group's Average (2) Latin America Region.

\begin{tabular}{|c|c|c|c|}
\hline & Coefficient & Ecartype & T-student \\
\hline FS & $0.392^{* *}$ & 0.167 & 2.33 \\
\hline EG & $3.70 * * *$ & 0.105 & 35.17 \\
\hline Popgrowth & 12.38 & 9.03 & 1.37 \\
\hline Democratie & -0.439 & 1.67 & -0.262 \\
\hline Vulprice & $-0.164 * * *$ & 0.01 & -14.99 \\
\hline CS & $-0.004 * * *$ & 0.0005 & -8.28 \\
\hline Constant & 7.65 & 94.16 & 0.08 \\
\hline
\end{tabular}

$* * *, * *$ and $*$ denote significance at respective rates of 1,5 and $10 \%$.

The above tables show the results of estimates of basic equation (1) and this is according to the average method of groups. The results show that the variable coefficients are highly significant except for the variable democracy.

The variable related to the supply of food delayedfor a period, shows positive and statistically significant impacts: a country that has increased its supply of food goods at time t1 given, exhibits a higher supply at time t.

The results show that the economic development level exhibits a positive and statistically significant impact on the variable supply of food, for all the regions. These results can be explained by the fact that the level of development reduces constraints to household access to food goods. In addition, a better economic development does not only increase investment in the food sector, Smith and Hadded (2000). However, 
the level of economic development increases the availability of food goods at national level and by importing more food. The results show that the Asian region has the highest impact of economic growth on FS. However, the African region has the lowest ratio since this region has not achieved good economic performance.

Our results confirm the thesis recognized by Merrick (2002) who found that the growth of the higher population is exacerbating the food supply by adopting inappropriate policies related to FS. Indeed, population growth is increasing the proportion of non-nourished population.

Regarding the variable related to democracy, it shows statistically not significant coefficients. This result was expected, given that most countries in our sample are characterized by an autocratic regime. Indeed, democracy can act on FS through economic growth, openness to trade, investment and human capital. (Pindick (1994), and Siroën Granger (2002), by Mankiw, Romer and Weil (1992) and Taveres and Wacziarg (1997)).

Regarding the volatility of rainfall, it shows negative and statistically significant coefficients on the FSvariable. The extent of this negative impact is higher for the African region which is characterized by levels of the lowest rainfall compared to other regions. According to Davis et al (2007) and World Bank (2006), between 60 and 100\% of resident households in African countries, work in the agricultural sector. This makes the African region a region more vulnerable to rainfall volatility relative to other regions. The predominance of agricultural production from rain-fed crops is highly sensitive to the volatility of rainfall.

The negative impact is explained by the fact that the rainfall volatility reduced agricultural output and household incomes. Similarly, the so-called volatility may reduce the proportion of fertile land and lower the performance of crop yields (Schmidhuber and Tubiello (2007)). In the same vein, poor weather conditions can have adverse effects on food production and availability.

The variable related to vulnerability to price shocks appears to have a negative and statistically significant impact on the dependent variable. These results can be explained by the fact that vulnerable countries have little fiscal space and administrative capacity toprotect their people against CCs ((de Janvry and Sadoulet (2008)). Indeed, the policy instruments that are available to facilitate access to food goods by increasing production or imports of agricultural goods are limited or ineffective.

The volatile $\mathrm{CC}$ reduces productivity and the supply of the majority of existing food and increases the proportion of the population that is already vulnerable to food insecurity. A country whose temperature levels are volatile (higher or lower) could in some cases be detrimental to the populations of certain regions. Vulnerability to CCs has an effect at the level of individual farms with the biophysical effects of this phenomenon on plants and animals. CC can have negative effects on local FS, and that, by making changes to local food prices.

Similarly, CC and volatile levels of precipitation can have significant effects on food productivity by causing different diseases of crops. The volatile $\mathrm{CC}$ should accentuate erratic rainfall, which is already harming livelihoods and production of a large number of rural families.

Another point to report showing that households are not all exposed to the same risks for FS. Vulnerability to food insecurity may be due to other external factors: biophysical and socioeconomic factors that impact on nutrition: the poor are more exposed to the impacts of $\mathrm{CC}$ leading to a deterioration of the social and economicsituation. CC affects more negatively the situation of people who have few resources and low income prospects, like small farmers and the landless rural women as well as the children of people living in rural areas. In the same vein, the majority of the poor are in SubSaharan Africa and South Asia, which are vulnerable to food insecurity linked to $\mathrm{CC}$. These regions are characterized by a weak social safety net. In some parts of Sub-Saharan Africa face risks related to changing and unstable climate, particularly droughts.

\section{CONCLUSION}

In this work, we examined the effects of climatic shocks on FS in the case of 54 developing countries over the period 1960-2014. View the heterogeneity observed in our sample, we used the average of the technical group proposed by Pesaran and Smith (1995) to overcome the heterogeneity bias. The results show that the rainfall is a volatility factor of food insecurity in developing countries. African countries appear to be the most vulnerable to CCs. Moreover, these same countries are also the most vulnerable to shocks in food goods prices.

FS can be defined as the capacity of all people to sufficient, healthy and nutritive food the physical and economic access. However, Agriculture, Food and Environment, these three words cannot be separated as the interdependencies reinforce in a world where everything is connected, everything speeds up and everything changes. The power issue is still essential because it is at the heart of human activity. In a world where natural resources suffer from the $\mathrm{CC}$ and population pressures, agricultural production has to deal increasingly with the imperative of quality

\section{CONFLICT OF INTEREST STATEMENT}

The authors declare that they have no conflict of interest.

\section{REFERENCES}

Ben Zaied, Y. and Zouabi, O. (2015), "Climate change impacts on agriculture: a panel cointegration approach and application to Tunis", MPRA Paper No. 64711.

Birdsall, N., Sinding, SW (2001), "How and why Population Matters: New Findings, New Issues", in Birdsall, N. Kelley, AC, Sinding, SW (Eds.), Population Matters: Demographic Change, Economic Growth and Poverty in the Developing World, Oxford University Press, New York.

Boserup, E. (1965), "The Conditions of Agricultural Growth: The Economics of Agrarian Change under Population Pressure".

George Allen \&Unwin, London. Brown, M. E. (2009), "Markets, CC, and FS in West Africa".About. Sci. Technol. 2009, 43, pp 8016-8020.

Ching, L. (2010), "CC Implications for Agriculture in Sub-Saharan Africa". Food and Agriculture Organization.

Dell, Melissa, Benjamin F. Jones and Benjamin A. Olken. (2008), "CC and economic growth: Evidence from last half century". Manuscript, MIT. 
Deschenes, Oliver and Michael Greenstone. (2007), "The economic impacts of CC: evidence from agricultural output and random fluctuations in weather," American Economic Review 97 (2), pp. 354-385.

Drèze, J., Sen, A. K. (1989), "Hunger and Public Action". Oxford University Press, Oxford.

Food and Agriculture Organization (2008), "CC and FS: a framework paper".

Gregory P.J, Ingram J.S. and Brklacich M. (2005), "CC and FS" .Phil. Trans. R. Soc. B 2005 360, pp. 2139-2148.

Kabubo-Mariara, J. and Kabara, M. (2015),"Climate change and food security in Kenya",

Environment for Development, Discussion Paper Series No. 15-05.

Kinda, S.R. (2017),"Climatic shocks and food security: the role of foreign aid", African Development Bank, Working Paper Series No. 286

Kurukulasuriya, P. et al. (2006), "Will African agriculture survive CC?".The World Bank Economic Review, 20 (3), pp. 367-388.

Kurukulasuriya, P. and Mendelsohn, R. (2008), "A Ricardian analysis of the impact of CC on African cropland" .African Journal of Agricultural and Resource Economics, 2 (1),pp 1-23.

Merrick, T.W. (2002), "Population and Poverty: New views on an old controversy." International Family Planning, Vol. 28 (1), pp. 41-46.

Malthus, T. R. (1993), "An Essay on the Principle of Population." Oxford University Press, Oxford (First edition 1798).

Mathieu, C. (2009), "The socio-economic determinants of hunger: a macro econometric analysis using panel data." 3 Development Days are the GRES, University Montesquieu Bordeaux IV, 10 to 12 June 2009.

Messer, E., Cohen, M. J., D'Costa, J. (1998), "Food from Peace.Breaking the Links Between Conflict and Hunger". Discussion paper and IFPRI Policy Brief for Vision 2020 on Food, Agriculture, and the Environment.

Mitchell, T. and Tanner, T. (2006), "Adapting to CC, Challenges and Opportunities for the Development Community". Institute of Development Studies and Tearfund, Teddington, UK.
B. Nagaraja C., Somashekar RK, and Kavitha. A. (2010), "Impact of Drought on Agriculture: Challenges facing poor farmers of Karnataka, south India". Environmental monitoring and assessment 170 (1-4), pp. 545-553.

Nhemachena, C., R. and Hassan Chakwizira J. (2009), "Economic Impacts of $\mathrm{CC}$ on Agriculture and Implications for FS in Southern Africa".Journal of Agricultural Extension , 46(2), pp.24-35.

Parliamentary Office of Science and Technology. (2006), "FS in Developing Countries".Postnote, 274 (19).

Pritchett, L. Summers, L. H. (1996), "Wealthier is Healthier," Journal of Human Resources, 31 (4), pp. 841-868.

Sen, A. K. (1999), "Development as Freedom". Oxford University Press, Oxford.

Seo, and N. Mendelsohn, R. (2008), "Animal husbandry in Africa: CC impacts and adaptations". African Journal of Agricultural and Resource Economics, 2 (1), pp. 65-82.

Singh, A. (2018)," Influence of climate and Non-Climatic factors on global food security index: a crosssectional country-wise analys ", Socialsci Journal, Vol. 1 No. 1, pp. 22-35.

H. E. Thompson, L. Berrang-Ford and Ford D. J. (2010), "CC and FS in Sub-Saharan Africa: A Systematic Literature Review". 2010 (2), pp. 2719-2733.

Tol J. S. (2009), "The Economic Effects of CC". Journal of Economic Perspectives-23, Number 2, pp. 29-51.

Wiesmann, D. (2006), "A Global Hunger Index: Measurement Concept, Ranking of Countries and Trends". FCND Discussion Paper, No. 12, IFPRI.

Wlokas, H.L. (2008), "The Impacts of CC on FS and Health in Southern Africa". J. Energy South. Afr. 2008, 19, pp. 12-20.

Pesaran, M.H. and R.P.Smith(1995), "Estimating Long-Run Relationships Heterogeneous Panels ", Journal of Econometrics, 68, pp. 70-113.

Received: May 02, 2021

Copyright $@$ 2021- All Rights Reserved

This is an open-access article. 